\title{
EFFECT OF ESOPHAGEAL DISTENTION ON PRESSURE AND ELECTROMYOGRAPHIC ACTIVITY OF THE PHARYNGOESOPHAGEAL SPHINCTER, WITH IDENTIFICATION OF THE ESOPHAGOPHARYNGEAL REFLEX
}

Ahmed Shafik, MD, PhD

\begin{abstract}
Purpose: My purpose was to study the effect of balloon-produced esophageal distention on the pharyngoesophageal sphincter to shed light on the mechanism by which esophagopharyngeal reflux is prevented. Method: Nine dogs (mean weight $15.7 \pm 4.3 \mathrm{~kg}$ ) were used for the study. A balloon-tipped catheter was introduced into the esophagus and a manometric catheter into the pharyngoesophageal sphincter. The pressure response of the pharyngoesophageal sphincter to esophageal distention was recorded. The response was also tested while the esophagus and the pharyngoesophageal sphincter were anesthetized, each separately. In six of nine dogs the electromyographic response of the pharyngoesophageal sphincter to esophageal distention was studied before and after the esophagus was anesthetized. Results: Lower and midesophageal distention produced no pressure changes in the pharyngoesophageal sphincter $(p=0.082)$. Upper esophageal distention effected an elevation in pharyngoesophageal sphincter pressure $(p=0.024)$, which showed no further rise when the distending volume was increased. The anesthetized pharyngoesophageal sphincter did not respond to esophageal distention. Likewise, the pharyngoesophageal sphincter did not respond to distention of the anesthetized upper esophagus. Esophageal distention produced increased electromyographic activity of the pharyngoesophageal sphincter, but no activity was recorded in response to distention of the anesthetized esophagus. Conclusion: This study has demonstrated contraction of the pharyngoesophageal sphincter on distention of the upper esophagus. This response seems to prevent esophagopharyngeal reflux and choking and is postulated to be evoked by means of an "esophagopharyngeal reflex." (J Thorac Cardiovasc Surg 1997; 114:968-74)
\end{abstract}

$\mathrm{S}_{\mathrm{s}}^{\mathrm{w}}$ wallowing is an intricate physiologic process designed for the transport of the food bolus from the pharynx to the stomach and for the prevention of esophagopharyngeal and gastroesophageal reflux. ${ }^{1}$ Four main phases of swallowing are recognized: preparatory, oral, pharyngeal, and esophageal. ${ }^{2}$ Swallowing is under the control of voluntary and reflex actions and of hormones. ${ }^{2-7}$ It could be elicited from the dorsum of the tongue, the epiglottis,

From the Department of Surgery and Experimental Research, Faculty of Medicine, Cairo University, Cairo, Egypt.

Received for publication Feb. 25, 1997; revisions requested July 11, 1997; revisions received July 23, 1997; accepted for publication July 24, 1997.

Address for reprints: Ahmed Shafik, MD, PhD, 2 Talaat Harb St., Cairo, Egypt.

Copyright (C 1997 by Mosby-Year Book, Inc.

$0022-5223 / 97 \$ 5.00+0 \quad \mathbf{1 2 / 1 / 8 5 0 4 8}$ the pillars of the fauces, the soft palate, and the wall of pharynx. ${ }^{8}$ It could also be induced by stimulation of the superior laryngeal nerve. ${ }^{9}$ Swallowing and respiration are interdependent processes at levels of central control ${ }^{10,11}$ and peripheral function. ${ }^{12-15}$ The importance of laryngeal valving during deglutition and its role in airway protection have long been recognized and studied. ${ }^{14-18}$

It has been demonstrated recently that pharyngeal distention evokes the pharyngoesophageal sphincter (PES) inhibitory reflex with a resulting opening of the PES. ${ }^{19}$ It is suggested that the action of this reflex allows for the passage of food boluses to the esophagus. Esophageal peristalsis transmits the food bolus down the esophagus. Peristaltic activity of the upper part of the esophagus might result in regurgitation of the esophageal contents into the pharynx.

The purpose of the present study was to study the 


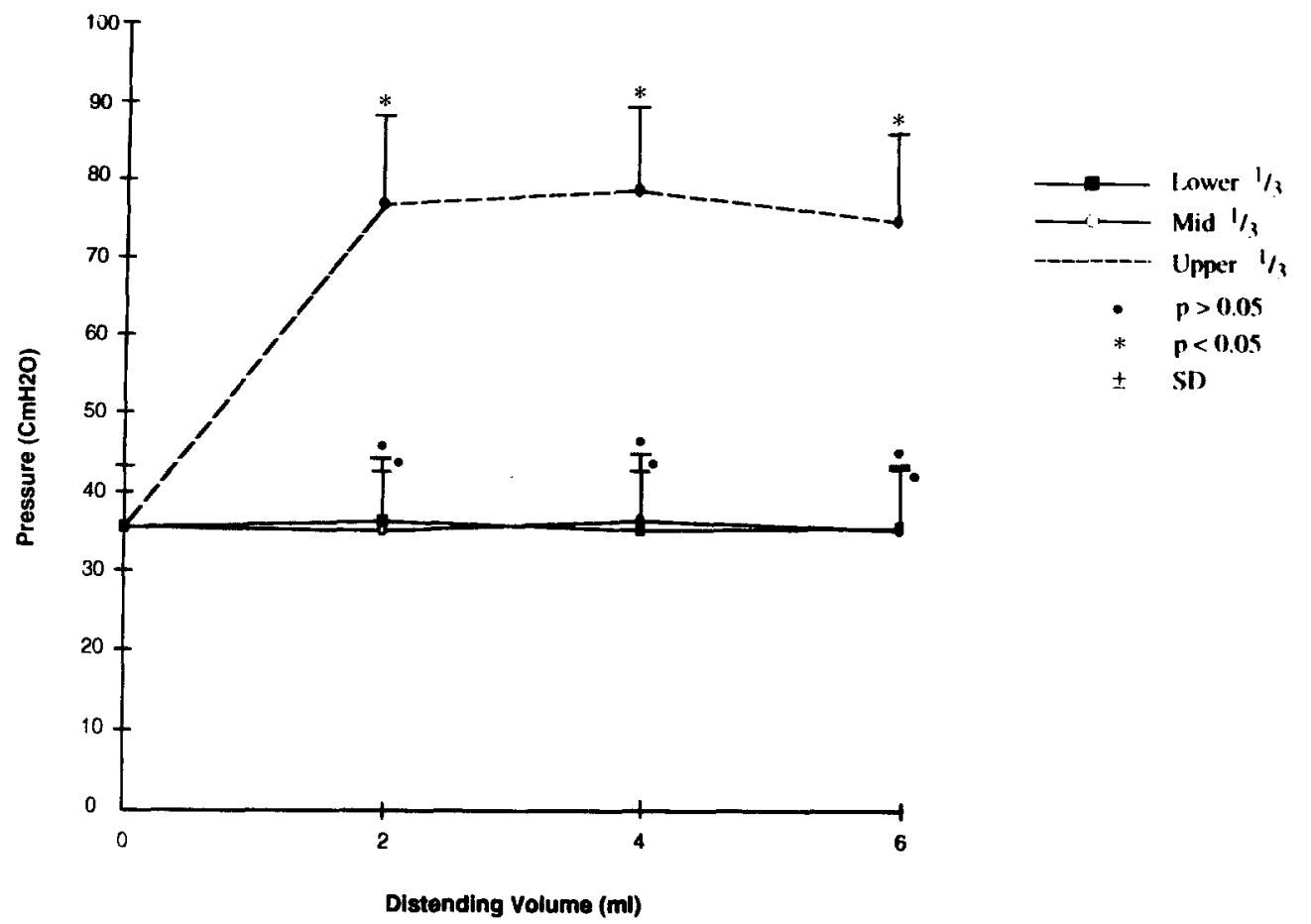

Fig. 1. Pressure within the PES on distention of the lower, middle, and upper thirds of the esophagus with a balloon filled with 2,4 , or $6 \mathrm{ml}$ of water in nine dogs. $S D$, Standard deviation.

effect of esophageal distention on the pressure within and the electromyographic activity of the PES. This might shed some light on the mechanism of prevention of esophagopharyngeal reflux.

\section{Material and methods}

Material. The study included nine dogs weighing from 12 to $17 \mathrm{~kg}$ (mean $15.7 \pm 4.3$ standard deviation). They were housed in cages and treated in compliance with "The Guide for Care and Use of Laboratory Animals." 20 The study was approved by the Faculty Review Board at Cairo University.

Methods. Each animal was anesthetized with pentobarbital sodium administered intravenously in a dose of 35 $\mathrm{mg} / \mathrm{kg}$ body weight. A balloon-tipped catheter was introduced into the esophagus. The balloon, made of latex and measuring $0.5 \mathrm{~cm}$ in diameter (London Rubber Industries Ltd.), had been tied to the distal end of a $4 \mathrm{~F}$ catheter, which was connected to a strain gauge pressure transducer (model 230b, Statham, Oxnard, Calif.). A metallic clip, applied to the catheter end close to the balloon, served to fluoroscopically control introduction and positioning of the catheter in the esophagus.

Manometric studies. A manometric $4 \mathrm{~F}$ catheter was introduced into the pharynx to lie within the PES. This catheter had two side ports and a metallic clip applied to its distal closed end. The catheter was connected to a pneumohydraulic capillary infusion system (Arndorfer Medical Specialities, Greendale, Wis.). The pump delivered saline solution continuously via the capillary tube at a rate of $0.6 \mathrm{ml} / \mathrm{min}$. The transducer outputs were registered on a rectilinear recorder (model RS-3400, Gould Inc.). Occlusion of the recording orifice produced a pressure elevation rate that was greater than $250 \mathrm{~cm}$ $\mathrm{H}_{2} \mathrm{O} / \mathrm{sec}$. During pressure measurements, the catheter was rotated so as to record anteroposterior and lateral pressures.

The manometric catheter was introduced first into the esophagus and then withdrawn to lie within the PES. A mechanical device was used for automatic withdrawal of the catheter at a rate of $6 \mathrm{~cm} / \mathrm{min}$ (model $9021 \mathrm{M}$, Disa, Copenhagen), and the pressure was measured during this withdrawal. While the catheter was being passed through the PES, the pressure rose, but the pressure then dropped when the catheter entered the hypopharynx. The tip of the manometric catheter was placed within the PES. The positioning of the catheter was done under fluoroscopic control when necessary.

The basal esophageal and PES pressures were recorded. The esophageal balloon was then filled with water in increments of $2 \mathrm{ml}$ up to $6 \mathrm{ml}$, and the PES pressure response was registered. Esophageal distention continued for 1 to 2 minutes depending on the duration of the PES response. The test was performed while the balloon was placed in the upper, middle, or lower third of the esophagus. The test was repeated at each site at least twice in the same dog to ensure reproducibility, and the mean of the readings was calculated.

Distention of the anesthetized esophagus and PES. The response of the PES to esophageal distention was tested while the esophagus and the PES were individually 


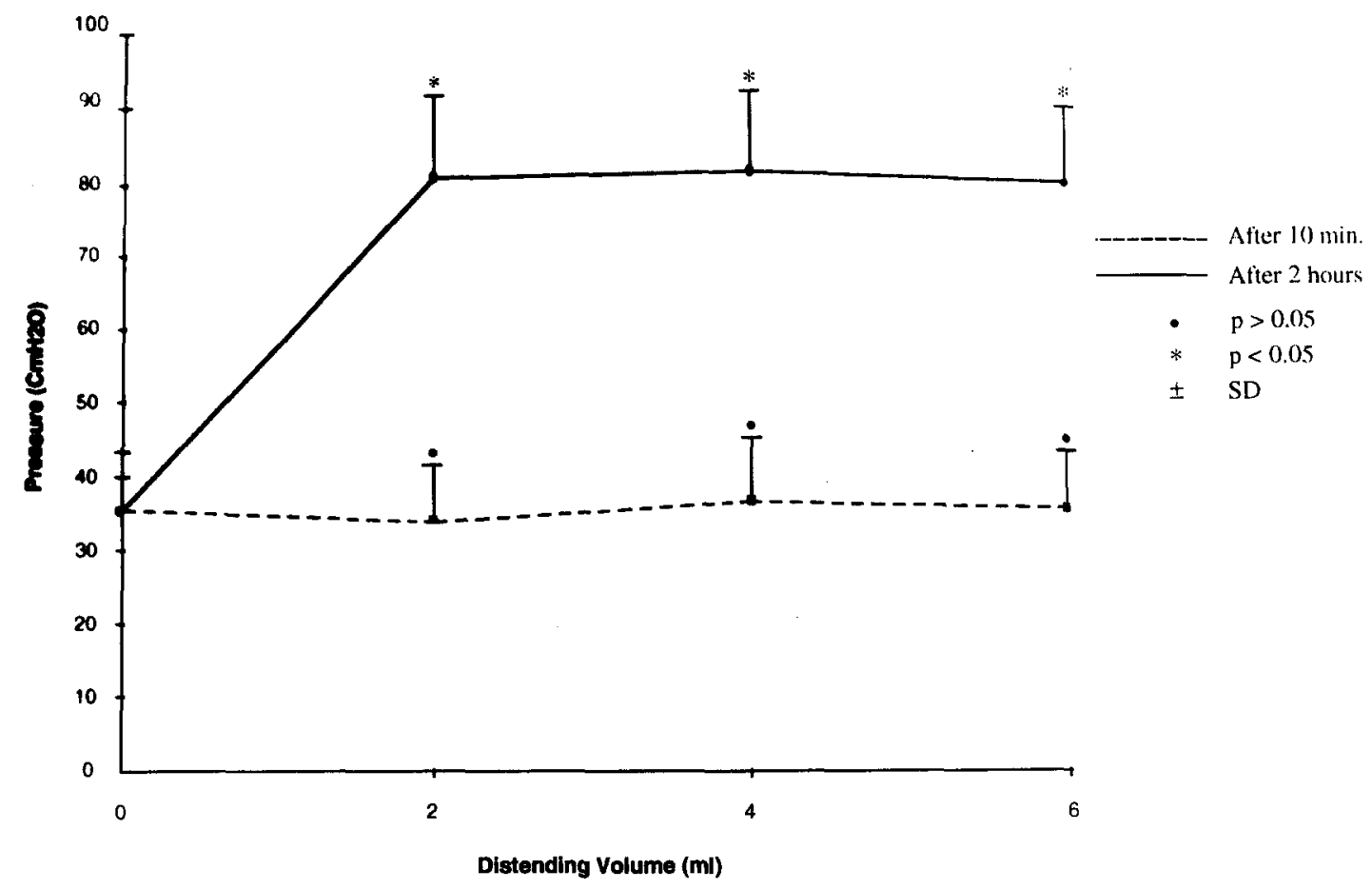

Fig. 2. Effect of distention of the upper esophagus on the pressure within the anesthetized PES, 10 minutes and 2 hours after anesthetic administration. $S D$, Standard deviation.

anesthetized, each at a different time. The PES was anesthetized in all the dogs by injection through an esophagoscope of $5 \mathrm{ml}$ of $2 \%$ lidocaine (Xylocaine) into the PES at multiple sites. The PES pressure response to distention of the upper, middle, and lower third of the esophagus was recorded after 10 minutes and 2 hours later when the anesthetic effect had waned. As the PES pressure responded to distention of the upper esophagus, the upper esophagus was anesthetized by injection through an endoscope of $5 \mathrm{ml}$ of $2 \%$ lidocaine at the site where the balloon was placed. The PES pressure response to balloon distention of the anesthetized esophagus was recorded 10 minutes and 2 hours after anesthetic administration. The test was repeated with saline solution injection into the PES and upper esophagus.

Electromyographic studies. The electromyographic response of the PES to esophageal distention was studied in six of the nine dogs. With the dog under general anesthesia, an oblique vertical incision along the sternocephalic (sternomastoid) muscle was made. The muscle and the carotid sheath were retracted laterally and the lobe of the thyroid gland was mobilized and retracted ventrally to expose the pharynx. The PES or the cricopharyngeal muscle was identified. This muscle arose from the lateral part of the arch of the cricoid cartilage and ended at the median raphe dorsally.

A concentric electromyographic needle electrode (type 13 L49, DISA, Copenhagen, Denmark) $40 \mathrm{~mm}$ in length and $0.65 \mathrm{~mm}$ in diameter was introduced into the PES. A ground electrode was applied to the hind limb. A standard electromyographic apparatus (type MES, Medelec, Woking, United Kingdom) was used to amplify and display the potentials recorded. Films of the potentials were taken on light-sensitive paper (Linagraph type 1895, Kodak) from which measurements of motor unit potential duration were obtained. The electromyographic signals were also stored on an FM tape recorder (type 7758A, HewlettPackard) for further analysis as required.

The normality of the electromyographic activity of the PES was tested before the experiment was performed. This was done by PES stimulation with a needle electrode introduced into the muscle and by registration of the motor action potentials from the already inserted needle electrode. In all examined animals the PES had normal electromyographic activity.

Esophageal distention. The esophageal balloon was filled with water up to $6 \mathrm{ml}$ in increments of $2 \mathrm{ml}$ and the electromyographic response (motor unit action potentials) of the PES to upper, middle, and lower third esophageal distention was recorded. The latency of the response was measured from the stimulus to the first deflection of the muscle action potential complex. Multiple recordings were made to ensure reproducibility. The part of the upper esophagus that contained the balloon was anesthetized by injection of $5 \mathrm{ml}$ of $2 \%$ lidocaine into the esophageal wall at multiple points. The electromyographic response of the PES to distention of this anesthetized part of the esophagus was registered after $10 \mathrm{~min}-$ utes and 2 hours later when the anesthetic effect had worn off. The test was repeated with injection of saline solution 


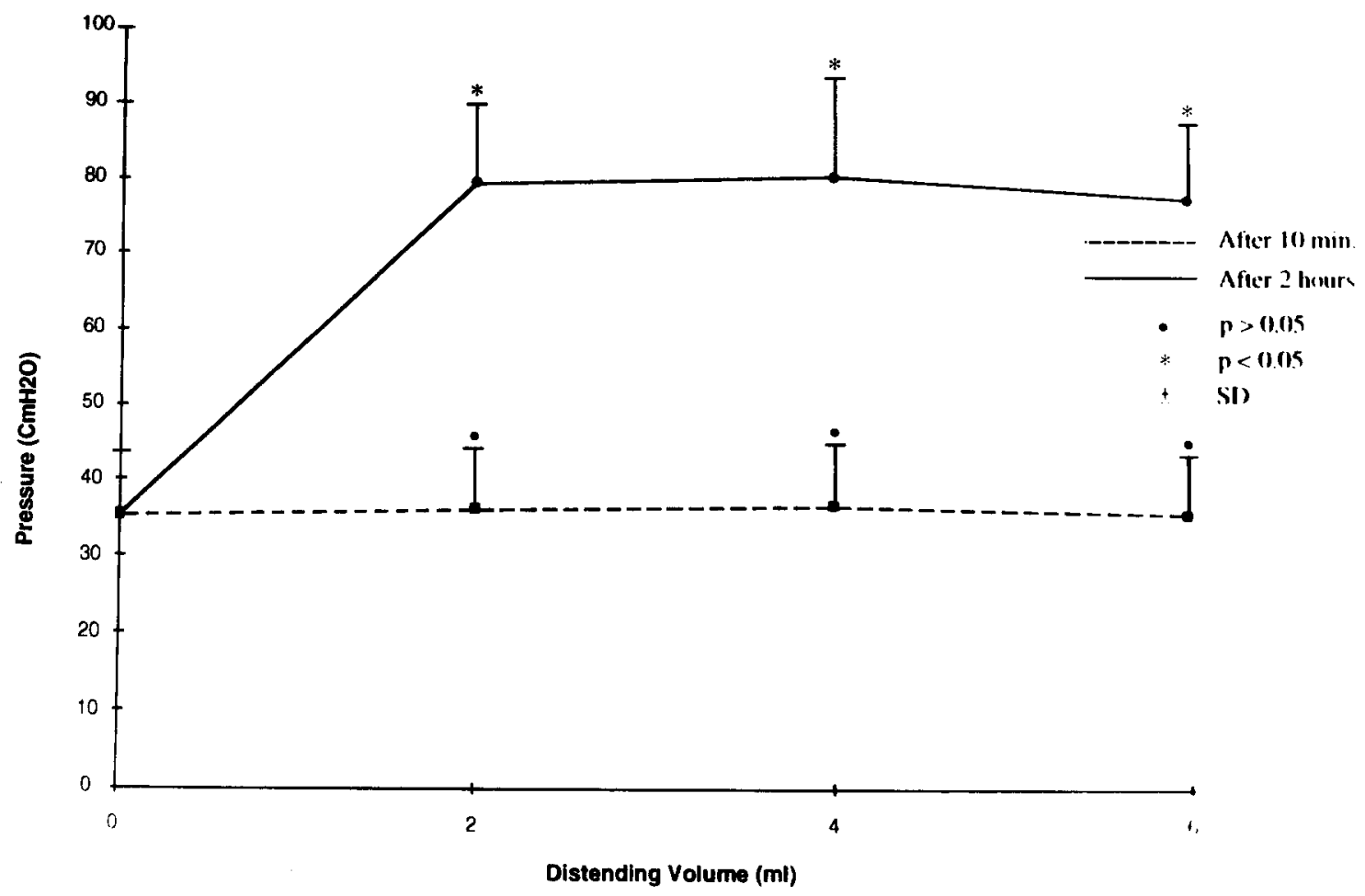

Fig. 3. Effect of distention of the anesthetized upper esophagus on the pressure within the PES, 10 minutes and 2 hours after anesthetic administration. SD, Standard deviation.

instead of lidocaine. After the aforementioned tests were completed, hemostasis was secured, the wound closed, and the animal allowed to awaken from anesthesia.

To assure reproducibility, the aforementioned recordings were repeated at least twice in each dog and the mean value was calculated. The results were analyzed statistically with the Student's $t$ test.

\section{Results}

No adverse effects of the protocol occurred in the animals during or after performance of the tests. The experiments were completed and evaluated in all dogs.

The mean basal PES pressure was $35.3 \pm 8.3 \mathrm{~cm}$ $\mathrm{H}_{2} \mathrm{O}$ (range 28 to 44 ) and the pharyngeal pressure $4.7 \pm 1.3 \mathrm{~cm} \mathrm{H}_{2} \mathrm{O}$ (range 3 to 8 ). Fig. 1 shows the pressure response of the PES to esophageal distention with 2, 4, and $6 \mathrm{ml}$ of water. Distention of the lower and middle third of the esophagus produced no significant pressure changes within the PES ( $p=0.082$; Fig. 1). Distention of the upper third of the esophagus with $2 \mathrm{ml}$ of water effected a significant PES pressure rise ( $p=0.024$, Fig. 1). Distention with 4 and $6 \mathrm{ml}$ of water produced a PES pressure rise that did not differ significantly from that produced by the $2 \mathrm{ml}$ distention ( $p=0.093$, Fig. 1). The PES pressure rise was maintained for 3 to 5 seconds (mean $4.2 \pm 1.1)$; the pressure then dropped to the predistention level $(p=0.086)$ even while the esophagus was still distended. The PES pressure response to repeated and successive esophageal distention could be evoked with no significant difference $(p=0.096)$, provided the distention started while the PES pressure was at the basal level.

Distention of the upper third of the esophagus did not produce significant pressure changes within the anesthetized PES ( $p=0.094$; Fig. 2). After 2 hours, when the anesthetic effect had waned, esophageal distention produced a PES pressure response similar to the response before administration of the anesthetic ( $p=0.085$; Fig. 2). Likewise, distention of the anesthetized upper third of the esophagus produced no significant pressure changes in the PES (Fig. 3). After 2 hours, however, the response returned and was similar to the preanesthetization response with no significant change $(p=0.076$; Fig. $3)$. The PES response to esophageal distention after 


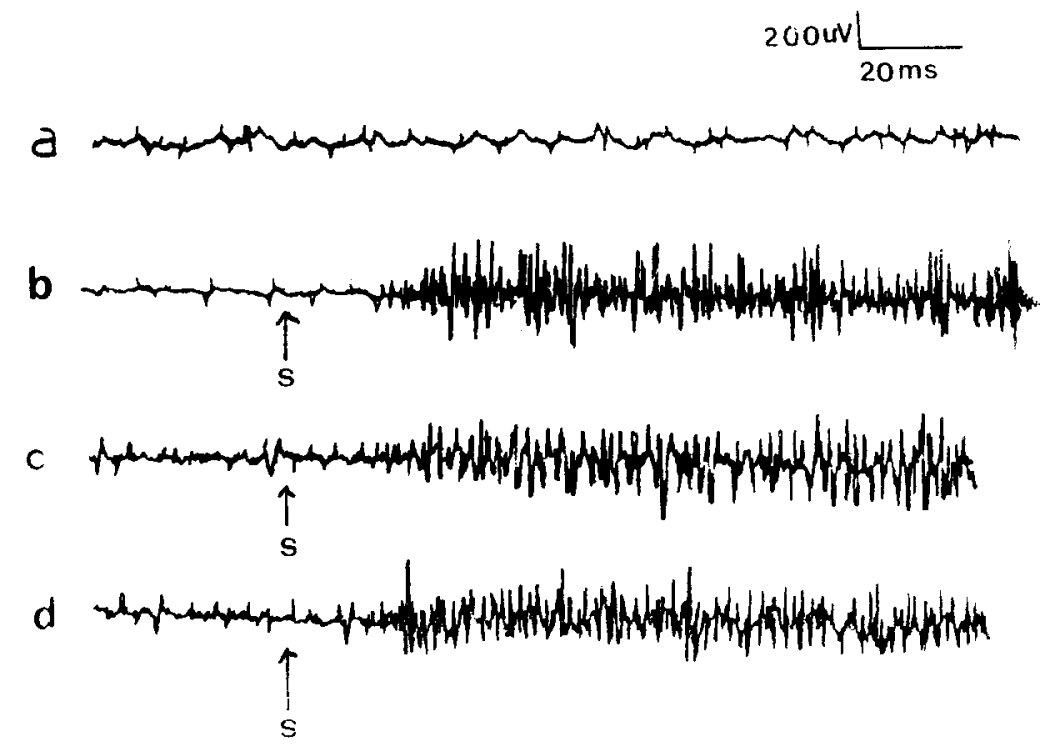

Fig. 4. Electromyographic activity of the PES on distention of the upper esophagus with 2, 4, and $6 \mathrm{ml}$ of water. a, Basal activity; b, $2 \mathrm{ml}$ distention; c, $4 \mathrm{ml}$ distention; d, $6 \mathrm{ml}$ distention. $s$, Stimulus.

saline solution infiltration of either the esophagus or the PES was similar to that before infiltration ( $p=$ 0.079).

Electromyographic response of the PES to esophageal distention. The PES had basal motor unit action potentials of 68 to $108 \mu \mathrm{V}$ (mean $84.4 \pm 18.5$; Fig. $4, a$ ). Distention of the lower or middle third of the esophagus with 2,4 , and $6 \mathrm{ml}$ of water did not effect a significant change in the electromyographic activity $(p=0.086)$. Distention of the upper third of the esophagus with $2 \mathrm{ml}$ of water produced an increase in motor unit action potentials of the PES to a mean of $412.8 \pm 92.4 \mu \mathrm{V}$ (range 318 to $585 ; p=$ 0.001 ; Fig. $4, b$ ), which was maintained for a period of 3 to 5 seconds (mean $4.6 \pm 1.2$ ) and then dropped to the basal level even when the esophagus was still distended. Repeated successive esophageal distention produced similar PES responses with no significant difference $(p=0.094)$. Esophageal distention with 4 and $6 \mathrm{ml}$ of water effected the same PES response as distention with $2 \mathrm{ml}(p=0.082$; Fig. 4, $c$ and $d)$. The latency or the period from the stimulus to the response varied from 12 to $17 \mathrm{msec}$ (mean $15.6 \pm 2.3)$ and did not exhibit a significant difference among the 2,4 , or $6 \mathrm{ml}$ distentions $(p=0.092)$. The PES did not respond to distention of the anesthetized upper third of the esophagus with any amount of water $(2,4$, or $6 \mathrm{ml})$; it responded 2 hours after anesthetization when the anesthetic effect had waned. Distention of the esophagus with infiltration of saline solution produced a PES response similar to that without infiltration.

The aforementioned results were reproducible with no significant difference $(p=0.095)$ when they were repeated in the same animal.

\section{Discussion}

The current study has demonstrated that the PES contracts on upper esophageal distention. This was evidenced by an increase in both the pressure and the electromyographic activity in the PES when the upper esophagus was distended. The PES contraction was not affected by the volume distending the esophagus. The response of the PES to esophageal distention has been recorded by other investigators. ${ }^{21-24}$ However, the electromyographic response of the sphincter to esophageal distention and its effect after anesthetizing the PES or the esophagus, each at a separate time, could not be traced in the literature.

The pressure and electromyographic responses of the PES to esophageal distention were momentary; they were maintained for seconds and then the values returned to predistention status even when esophageal distention continued. However, the responses were evoked with repeated successive esophageal distention provided this was done while the PES was in the basal state. Distention of the middle and lower third of the esophagus evoked no pressure or electromyographic response in the PES. 
The PES contraction on upper esophageal distention postulates a reflex relationship between the two actions. The constancy of this reflex relationship is evidenced by its reproducibility and by its absence when the upper esophagus and PES, the two suggested arms of the reflex, were anesthetized. I call this reflex relationship the "esophagopharyngeal reflex." It seems that upper esophageal distention stimulates stretch receptors in the esophageal wall that evoke the reflex PES contraction. The stimulation of the stretch receptors is probably not affected by the increase in the distending volume of the esophagus. The PES response was also the same with repeated and successive distention of the upper esophagus. This might indicate a nonfatigability of the response.

Role of the esophagopharyngeal reflex in deglutition. As already mentioned, pharyngeal distention evokes the PES inhibitory reflex with a resulting PES relaxation. ${ }^{19}$ The PES opening is momentary, allowing for the passage of the bolus to the esophagus, and is followed by spontaneous closure. The current study has shown that upper esophageal distention is associated with momentarily increased PES pressure and electromyographic activity. This suggests that upper esophageal distention by the food bolus induces PES contraction, which probably acts to prevent reflux of the esophageal contents to the pharynx and hence a possible choking.

The PES contracts only with upper esophageal distention. It thus prevents regurgitation of the upper esophageal contents to the pharynx that might result from the peristaltic activity of the esophagus. The PES does not contract with distention of the middle or lower esophagus because the danger of esophagopharyngeal reflux probably does not exist. Studies have shown that patients with esophagopharyngeal regurgitation have PES hypotension and diminished sphincter response to intraesophageal fluid. ${ }^{24,25}$

The nonfatigability of the PES by repeated stimulation is believed to be an advantage. The pharynx and the esophagus receive multiple food boluses during the process of ingestion. The successive arrival of food boluses in the pharynx generates repeated PES dilations and contractions. The brevity of the PES response seems to preserve sphincter energy and avoid fatigue, in particular because the PES is a striped muscle that fatigues easily.

The role of the esophagopharyngeal reflex during vomiting needs to be discussed. There are four main stages of the vomiting reflex ${ }^{26}$ : (1) diaphragmatic descent, (2) stomach and lower esophageal sphincter relaxation and abdominal wall muscle contraction, (3) esophageal longitudinal muscle contraction, and, finally, (4) gastric antrum contraction and PES relaxation. It is thus apparent that, during vomiting, the normal physiologic mechanism of esophageal motility is disturbed, including PES action. As the vomited bolus reaches the upper esophagus, the PES relaxes instead of contracting as occurs under normal conditions. If the PES, on receiving the bolus during vomiting, failed to relax, spontaneous rupture of the esophagus might occur. The cause of the relaxing response of the PES to the vomited bolus is not known. It might be that the sphincter is involved in the esophageal antiperistaltic activity that occurs during vomiting. Alternatively, the nature of the refluxing material (acid, bile) might be responsible for the PES response. However, investigators have demonstrated an increase of the PES pressure on intraesophageal infusion of hydrochloric acid. ${ }^{24}$

In conclusion, upper esophageal distention produces PES contraction, which is suggested to be evoked by means of the esophagopharyngeal reflex. The latter probably acts to prevent esophagopharyngeal reflux.

Margot Yehia and Waltraut Reichelt assisted in preparing the manuscript.

\section{REFERENCES}

1. Kellow JE. Mastication and swallowing. In: Greger R, Windhorst $\mathrm{U}$, editors. Comprehensive human physiology. Berlin: Springer-Verlag; 1996. p. 1233-7.

2. Cook IJ. Normal and disordered swallowing. In: Dent J, editor. Practical issues in gastrointestinal motor disorders. Baillieres Clin Gastroenterol 1991;5:245-67.

3. Miller AJ. Deglutition. Physiol Rev 1982;62:129-34.

4. Weisbroat NW. Gastrointestinal motility. Annu Rev Physiol 1981;43:7-19.

5. Udekwu AO. Gastrointestinal physiology. In: Simmons RL, Steed DL, editors. Basic science review for surgeons. Philadelphia: WB Saunders; 1992. p. 229-31.

6. Christensen J. Motor functions of the pharynx and esophagus. In: Johnson LR, editor. Physiology of the gastro-intestinal tract. Raven, New York; 1987. p. 595-612.

7. Cook IJ, Dodds WJ, Daukas RO, et al. Timing of videofluoroscopic manometric events and bolus transit during the oral and pharyngeal phases of swallowing. Dysphagia 1989;4:8-15.

8. Miller FR, Sherrington CF. Some observations on the buccopharyngeal stage of reflex deglutition in the cat. Q J Exp Physiol 1916;9:147-86.

9. Doty RW. Influence of stimulus pattern on reflex deglutition. Am J Physiol 1951;166:142-58. 
10. Sumi T. The activity of brain-stem respiratory neurons and spinal respiratory motoneurons during swallowing. J Neurophysiol 1963;26:466-77.

11. Doty RW, Richmond W, Storey A. Effect of medullary lesions on coordination of deglutition. Exp Neurol 1967;17: 91-106.

12. Selley W, Flack F, Ellis R, Brooks W. Respiratory patterns associated with swallowing: part 1-the normal adult pattern and changes with age. Age Ageing 1989;18:168-72.

13. Nishino T, Yonezawa T, Honda Y. Effects of swallowing on the pattern of continuous respiration in human adults. Am Rev Respir Dis 1985;132:1219-22.

14. Adran G, Kemp F. The protection of the laryngeal airway during swallowing. Br J Radiol 1952;25:406-16.

15. Clark G. Deglutition apnoea. J Physiol (Lond) 1920;54:5968.

16. Adran $G$, Kemp F. Closure and opening of the larynx during swallowing. Br J Radiol 1956;29:205-8.

17. Shaker R, Dodds W, Dantas R, Hogan W, Arndorfer R. Coordination of deglutitive glottic closure with oropharyngeal swallowing. Gastroenterology 1990;98:1478-84.

18. Martin BJW, Logemann JA, Shaker R, Dodds WJ. Normal laryngeal valving patterns during three breath-hold maneuvers: a pilot investigation. Dysphagia 1993;8:11-20.
19. Shafik A. Recognition of a pharyngo-oesophageal sphincter inhibitory reflex in dogs and its role in deglutition. Exp Physiol 1995;80:249-53.

20. The Guide for Care and Use of Laboratory Animals. Baltimore: U.S. Public Health Services (NIH publication no. 1). 1989. p. 5-23.

21. Creamer B, Schlegel J. Motor responses of the esophagus to distension. J Appl Physiol 1957;10:498-504.

22. Enzmann DR, Harell GS, Zboralske FF. Upper esophageal responses to intraluminal distention in man. Gastroenterology 1977;72:1292-8.

23. Freiman JM, El-Sharkawy TY, Diamant NE. Effect of bilateral vagosympathetic nerve blockade on response of the dog upper esophageal sphincter (UES) to intraesophageal distention and acid. Gastroenterology 1981;81:78-84.

24. Gerhardt DC, Castell DO, Winship DH, Shuck TJ. Esophageal dysfunction in esophagopharyngeal regurgitation. Gastroenterology 1980;78:893-7.

25. Kilman WS, Goyal RK. Disorders of pharyngeal and upper esophageal sphincter motor function. Arch Intern Med 1976; 136:592-601.

26. Kellow JE. Gastrointestinal motility and defecation. In: Greger R, Windhorst U, editors. Comprehensive human physiology. Berlin: Springer-Verlag; 1996. p. 1289-308.

\section{Availability of Journal back issues}

As a service to our subscribers, copies of back issues of The Journal of Thoracic and Cardiovascular Surgery for the preceding 5 years are maintained and are available for purchase from Mosby at a cost of $\$ 15.00$ per issue until inventory is depleted. The following quantity discounts are available: $25 \%$ off on quantities of 12 to 23, and one third off on quantities of 24 or more. Please write to Mosby-Year Book, Inc., Subscription Services, 11830 Westline Industrial Drive, St. Louis MO 63146-3318, or call 800-453-4351 or 314-453-4351 for information on availability of particular issues. If unavailable from the publisher, photocopies of complete issues may be purchased from UMI, 300 N. Zeeb Rd., Ann Arbor, MI 48106, 313-761-4700. 